\title{
Student Predisposition to Instructor Feedback and Perceptions of Teaching Presence Predict Motivation Toward Online Courses
}

\author{
Andrew William Cole \\ University of Wisconsin-Whitewater \\ Kristine M. Nicolini \\ University of Wisconsin-Oshkosh
}

\begin{abstract}
Christopher Anderson, Thomas Bunton, Maura R. Cherney, Valerie Cronin Fisher, Richard Draeger, Jr., Michelle Featherston, Laura Motel, Brittnie Peck, and Mike Allen University of Wisconsin-Milwaukee
\end{abstract}

\begin{abstract}
Much research into college student motivation focuses on traditional face-to-face (FtF) classroom settings. Building from previous research in Feedback Intervention Theory (Kluger \& DeNisi, 1996) and the Community of Inquiry framework (Anderson, Rourke, Garrison, \& Archer, 2001; Garrison, Anderson, \& Archer, 1999), this study sought to identify predictors of student motivation toward online courses. Results from a hierarchical multiple regression, using data from 190 online undergraduate students, suggest that student predisposition to receiving instructor feedback and student perceptions of teaching presence provide strong prediction of student motivation toward online courses. However, perceptions of teaching presence did not predict motivation in the hypothesized direction. These findings support the notion that the online learning environment offers its own unique set of challenges and opportunities, and warrants continued empirical research beyond comparisons to $\mathrm{FtF}$ classroom settings.
\end{abstract}

Keywords: Instructor feedback, teaching presence, student motivation, online courses, instructorstudent communication

Cole, A. W.; Allen, M.; Anderson, C.; Bunton, T.; Cherney, M. R.; Draeger, Jr., R.; Featherston, M.; Fisher, V. C.; Motel, L.; Nicolini, K. M. \& Peck, B. (2017). Student predisposition to instructor feedback and perceptions of teaching presence predict motivation toward online courses. Online Learning, 21(4), 245-262. doi: 10.24059/olj.v21 i4.966 


\section{Student Predisposition to Instructor Feedback and Perceptions of Teaching Presence Predict Motivation Toward Online Courses}

As increasing numbers of students enroll in online courses (Allen \& Seaman, 2015; U.S. Department of Education, 2014), much academic discussion contrasts positive and negative aspects of online teaching and learning. New online course delivery methods such as Massively Open Online Courses (MOOCs) appear and generate additional widespread debate before a body of empirical research is conducted (Cole \& Timmerman, 2015). In order to maximize positive student outcomes, strategies and philosophies toward course design, and facilitation, must be evaluated and updated with findings gained from empirical testing. Less research focuses on student experiences in online courses than face-to-face (FtF) courses (Otter et al., 2013). Solely critiquing online courses, particularly on how they are perceived to fall short of traditional FtF learning experiences, offers little in the way of promoting positive student outcomes for those students enrolling in online courses. Rather, research focused on identifying specific predictors of positive student affect online is warranted on determining how to maximize student outcomes for those enrolled in online courses.

Without question online teaching and learning represents a change in the instructional context from the traditional FtF classroom. In online courses, mediated communication provides the primary means for student-instructor communication, and reflects a potentially novel computer-mediated student-instructor relationship (Sherblom, 2010). Further, the way in which students perceive current online instructors may well relate to how they perceive online courses. Though student-instructor communication takes place differently online than $\mathrm{FtF}$, perceptions of instructor communication appear related to student outcomes regardless of modality (Cole, 2016; Hazel, Crandall, \& Caputo, 2014). Previous research (Cole, Kim, \& Priddis, 2015) even suggests that how students perceive the online student-instructor relationship may predict student likelihood to enroll in another online course. The current study examined the predictive influence of students' predispositions to instructor feedback and perceptions of teaching presence, in a current online course, on student motivation toward online courses. The findings from this research provide a basis for future inquiry into online course communication as well as student motivation in online courses.

\section{Online Course Structure}

Much as in traditional FtF courses, students beginning online courses must acclimate to the instructor, course content, and other students in the class. However, students in online courses must also adapt to the online course design and interface (e.g., the course management system; CMS). Though the "digital natives" notion toward student technology use and learning lacks full empirical support (Thompson, 2013), generational stereotypes that current college students are intrinsically comfortable, and competent, with using technology in learning continue to circulate throughout colleges and universities. Such stereotypes can serve to underplay the challenges that many students face when taking an online course for the first time. Many students may be uncomfortable with some technology, and also simply prefer the FtF modality when given the option. Several studies suggest that students, in general, appear to prefer FtF communication, and the traditional FtF modality (Allen, Bourhis, Burrell, \& Mabry 2002; Cole, 2016; Morreale, Staley, Stavrositu, \& Krakowiak, 2015). Even for students comfortable with technology, online courses, and the corresponding computer-mediated student-instructor relationships, may simply not be a first choice in their education. 
Online course structures may represent one reason that students may prefer traditional FtF courses. In FtF courses, students and instructors have no option but to synchronously interact with each other beginning on the first day of class. These first day FtF interactions may well set communication expectations for the class for the entire semester (Haleta, 1996). Conversely, in online courses, students are likely to "attend" the first "class meeting," asynchronously through technology like a CMS, at any point during the first week of classes, and perhaps even later. As long as a course is facilitated 100\% online (e.g., not a "hybrid" or "blended" course that also implements FtF interactions in a traditional classroom setting), any synchronous instructor-student communication takes place through a mediated channel (i.e., web conferencing software). As the online course structure requires students and instructors largely to communicate asynchronously, expectations for communication, and therefore the class communication climate, likely develops differently online than FtF (Mandernach, Gonzales, \& Garrett, 2006). Further, online course structures that allow students to complete mastery-based tasks at their own pace, with little peerto-peer interaction (see Reddy et al., 2013) further complicate traditional notions of class meetings, attendance, and communication in online courses.

Not only does the online course structure challenge many students, but many instructors find the course structure challenging as well. Preparing and delivering an online course often takes instructors, especially instructors new to teaching online, longer than preparing a comparable FtF course (Bolliger \& Wasilik, 2009). Online instructors often lay out course schedules, complete with learning activities, for the entire semester in advance so that students can view the course structure, expectations, and assignments beginning on the first day of class. As a result, the rigid structure and asynchronous communication often prevents the opportunity to immediately change course direction based on student input (Easton, 2003). Aside from preparation and design issues, many online instructors may struggle in adapting instructional identities, fashioned FtF, to computer-mediated communication and online courses (Anderson et al., 2001; Easton, 2003; Sherblom, 2010).

The challenges faced by students and instructors in online courses described above underscore how simply contrasting positive and negative aspects of online courses with $\mathrm{FtF}$ courses does little to assist those currently learning and teaching in the modality. Not only are students and instructors both challenged by the modality, but they might not even conceptualize online course expectations in the same way. Some previous research suggests that students and instructors perceive online courses differently, with students viewing the online course format as more student self-directed and autonomous than their instructors do (Otter et al., 2013). Research that aids in better understanding how students perceive their online instructors (i.e., "teaching presence") can potentially help address some of the challenges and obstacles associated with online learning from the student perspective.

\section{Teaching Presence}

The teaching presence construct arises from the Community of Inquiry framework for online learning (CoI; Anderson et al., 2001; Garrison, Anderson, \& Archer, 1999). In the CoI framework, teaching presence represents one dimension of presence, along with cognitive presence and social presence (Anderson et al., 2001; Garrison, Anderson, \& Archer, 1999; Garrison, Cleveland-Innes, \& Fung, 2010; Vaughan, Cleveland-Innes, \& Garrison, 2013). Though the terms "teaching presence" and "social presence" are often used interchangeably, the CoI framework distinguishes teaching presence as focused on student perceptions of online instructor communication and course direction. Conversely, social presence recognizes a larger social 
environment present within an online course. Unlike teaching presence, social presence includes how online student communication behaviors contribute to creating a positive learning environment in an online course.

According to Anderson et al. (2001), students perceive teaching presence through course design, which largely takes place before the course begins, and how the instructor guides student discussion on course material throughout the semester. Shea, Li, and Pickett (2006) developed a teaching presence scale based on Anderson et al.'s notion of teaching presence and found two distinct components. The researchers calculated that the two dimensions of "instructional design and organization," and "directed facilitation" (p. 181) accounted for 78\% of the variance in the teaching presence construct. Shea et al.'s quantitative findings compliment findings from previous qualitative research by Easton (2003) suggesting that online instructors serve as course designers and learning facilitators. Thus, student motivation toward online courses may be positively influenced by online instructors who can design an environment that clearly and competently communicates course expectations, as well as instructors who can effectively guide and moderate student discussion on the course material. Given the challenges of the online course structure, and the potential for teaching presence to influence student motivation, another area of interest therefore becomes how online instructor feedback can influence student motivation toward online courses.

\section{Student Predisposition to Instructor Feedback}

Teaching presence relates to student perceptions of specific instructors and specific courses. Therefore, a student's perception of instructor teaching presence could, and likely would, vary between instructors and courses. Conversely, student predisposition toward instructor feedback represents a more generalized student affective response which likely varies little instructor-to-instructor. Instructor feedback assesses student performance on learning activities, and provides guidance on how students can improve for future performance. Previous research suggests that students vary in receptiveness to corrective instructor feedback, making giving and receiving feedback a challenging process for instructors and students alike (King, Schrodt, \& Weisel, 2009; Malachowski, Martin, \& Vallade, 2013; Robinson, Pope, \& Holyoak, 2013; Smith $\&$ King, 2004). Some students may respond to corrective instructor feedback by feeling motivated to improve future performance, while others may discount the feedback through avenues such as questioning the instructor's grading practices (Malachowski et al., 2013), or even perform worse in future performance (King, 2016).

The use of nonverbal behaviors, such as eye contact, is not typically feasible in most online course formats, given the particulars of the communication channel. Though online instructors may often engage in mediated nonverbal immediacy behaviors, such as using text-based "smiley faces," students may never look at the instructor's feedback on a specific assignment, beyond seeing a grade for the assignment in the CMS. As the type of asynchronous computer-mediated communication prevalent in online courses largely lacks the ability to accommodate instructor nonverbal immediacy behaviors in the same way as FtF (Pratt et al., 1999; Sherblom, 2010), students may not perceive instructor attempts at face-threat management in the feedback they receive in online courses. Students could even perceive clear, directive feedback as more facethreatening when received online than $\mathrm{FtF}$, as instructors have less opportunity to visibly and skillfully incorporate face-mitigating techniques (King, Schrodt, \& Weisel, 2009; Kerssen-Griep \& Witt, 2012; Trees, Kerssen-Griep, \& Hess, 2009). Though some research suggests that students appreciate clear and direct instructor communication regardless of course modality (Poulos \& 
Mahony, 2008; Sheridan \& Kelly, 2010), clear instructional feedback may not be enough to motivate students to engage the course material (Bolkan, Goodboy, \& Kelsey, 2016). Therefore, further research examining how student predisposition toward instructor feedback could influence student affect toward online courses is necessary.

Instructor corrective feedback provides students with an assessment of the student's current mastery of course competencies, and guidance for improving future performance, but also may represent one of the primary means of instructor-student communication in online courses. As previous research suggests that instructor feedback directly relates to student motivation in a course (Dennen, 2005; Hosler \& Arend; 2012), research specifically examining the predictive influence of student predisposition to instructor feedback on motivation toward online courses is warranted. The current research builds from Feedback Intervention Theory (FIT; Kluger \& DeNisi, 1996). FIT suggests that corrective feedback may increase or decrease subsequent performance depending on message content and context. Kluger and DeNisi conducted a meta-analysis on feedback interventions (FIs), situations where feedback served to guide future performance. The researchers found general support for a positive relationship between corrective feedback and performance. However, the researchers also found that when feedback messages focused on specific areas where participants fell short of expectations (labeled "feedback-standard gaps"), corrective feedback actually decreased later performance. In addition to providing guidance on course content, instructor feedback may serve as a means of developing rapport between students and instructors in online courses (Frisby, Limperos, Record, Downs, \& Kerscmar, 2013). As student-instructor communication generally appears to serve a relationship function (Frymier \& Houser, 2000; Morgan \& Manusov, 2009), findings testing FIT may suggest that how students generally react to corrective instructor feedback may also predict motivation toward online courses.

Student perceptions of, and predispositions to, instructor feedback appear rooted in several different modes through which students process feedback. Further developing FIT for educational applications, King et al., (2009) divided student perceptions of feedback into four categories: retention, confidentiality, sensitivity, and utility. The first category, retention, describes the degree to which students remember the specific content of the instructor's feedback. The second category, confidentiality, describes the degree of privacy maintained for the feedback message between the instructor and student (i.e., whether the feedback was delivered in front of other students). The third category, sensitivity, describes how open students are toward receiving, and accepting, corrective feedback. The final category, utility, describes the degree to which students perceive the feedback as helpful going forward. As King et al.'s four feedback categories were tested in traditional FtF classroom settings, research is necessary to determine whether the same categories carry over to online courses.

As students can perceive instructor feedback as face-threatening (King et al., 2009; Trees et al., 2009), corrective feedback as primary means of instructor-student communication in online courses may present an obstacle to instructor-student relational development (Frymier \& Houser, 2000). To that end, the current study examines whether student predisposition to instructor feedback predicts student motivation toward online courses.

\section{Motivation}

The current study examines whether student perceptions of teaching presence in current online courses and predisposition to instructor feedback predict student motivation toward online 
courses. Student motivation, as operationalized in the traditional FtF context, generally consists of two components: trait motivation, and state motivation. Trait motivation represents a general motivation toward learning; while state motivation represents motivation toward a specific course (Brophy, 1983). In one study, Christophel (1990) studied the relationship between instructor verbal and nonverbal immediacy and student motivation toward specific FtF courses (e.g., state motivation). Christophel concluded that, even though students may enter a course with varying levels of trait motivation, instructors' communication behaviors (ex. nonverbal immediacy behaviors) influence students' motivation toward the specific course. These findings were later reinforced through Christophel and Gorham's (1995) study, which found that perceptions of instructors' verbal immediacy strongly influenced students' state motivation. Christophel and Gorham therefore suggest that student trait motivation is viewed largely by students as dependent on the student, however state motivation appears to be viewed by students as largely dependent on the instructor.

Little prior research examines predictors of affective student variables, like motivation, in online courses. The role of motivation, as an affective learning outcome, potentially serves an important role in understanding effectiveness in generating educational outcomes (Allen, Witt, \& Wheeless, 2006; Allen, Mabry, Mattrey, Bourhis, Titsworth, \& Burrell, 2004). Allen et al.'s (2006) meta-analysis testing a causal model found that higher instructor immediacy predicted affective learning, which predicted higher cognitive learning in FtF courses. Further research in FtF courses on student motivation supports the notion that students' perceptions of the instructor's communication behaviors can influence students' motivation in a course (Christophel \& Gorham, 1995; Frymier \& Houser, 2000; Martin, Chesebro, \& Mottet, 1997). However, research is necessary to identify predictors of affective student outcomes online as well.

\section{Study Hypotheses}

Anderson et al., (2001) suggest that how instructors communicate online can influence student motivation. Further, how students perceive the online instructor-student relationship appears to predict whether they would report intention to enroll in another online course (Cole, Kim, \& Priddis, 2015). The current study considered student predisposition toward instructor feedback and perceptions of teaching presence as potential predictors of student motivation toward online courses.

The first study hypothesis considers the predictive influence of individual online course experiences on student motivation toward online courses more generally. Previous research suggests that student motivation $\mathrm{FtF}$ may be modifiable by instructor communication behaviors (Allen et al., 2006; Christophel, 1990; Christophel \& Gorham, 1995). Teaching presence (Anderson et al., 2001; Garrison et al., 1999; Shea et al., 2006) offers an avenue to measure students' perceptions of instructor communication behavior in online courses. Student online courses experiences, and perceptions of online instructors, may carry over motivation toward online courses more generally. Therefore, the first hypothesis predicts that higher levels of student perceived teaching presence in current online courses will predict higher student motivation toward online courses more generally.

\section{H1: Students who perceive higher levels of teaching presence in current online courses} will demonstrate higher levels of motivation toward online courses more generally.

The second study hypothesis considers the predictive influence of a more generalized student trait on student motivation toward online courses. In line with FIT (Kluger \& DeNisi, 
1996), instructor feedback could potentially decrease student motivation depending on how students react to the feedback. Additionally, online courses do not offer the same means for instructors to personally deliver corrective feedback, which may lessen face-threats to students (Kerssen-Griep \& Witt, 2012; King et al., 2009; Trees et al., 2009). Therefore, the second hypothesis predicts that students who react negatively to instructor feedback will be less motivated toward online courses.

\section{H2: Students who react negatively to instructor feedback will demonstrate lower levels of motivation toward online courses.}

\section{Methods}

\section{Participants and Procedures}

Following IRB approval, participants for the study were recruited from a large, urban, public university through online undergraduate communication courses. The university offers multiple degree completion programs online, including the communication major. However, students attending the university could enroll in online communication courses even if not participating in online degree programs. The study data were collected utilizing the Qualtrics online survey instrument. The online survey instrument was used so that participants not enrolled in any FtF courses, and who might not ever physically attend campus, could still take part in the research study. Some students received a small amount of extra credit for taking part in the study, dependent on the course instructor who advertised the study. No additional incentives for participation in the research were offered by the researchers.

Given the study design, it was necessary for participants to report on a specific course for the teaching presence measure. Plax, Kearney, McCrosky, and Richmond's (1986) approach where students complete measures based on the most recent class they attended was modified for the online context, so that students reported on the specific online course through which they received the study link. However, it was necessary to ensure students that their answers would not influence their relationships with their instructors, and/or their grades in the course. Students were therefore informed at the beginning of the survey that they would not be identified with their responses, and their current instructors would not have access to their specific responses.

The total number of participants who took part in the study was 190. Females made up the majority of the sample $(n=100)$. The sample participants included students at all educational levels: freshman $(n=13)$; sophomore $(n=44)$; junior $(n=52)$; seniors $(n=64)$, with 17 participants not reporting a college year. The majority of the sample $(n=135)$ reported traditional college ages between 18-25, with 26 students reporting ages between 26-35, 11 students reporting ages between 36-45, and one student reporting an age of 45 or older.

\section{Measures}

The online survey consisted of 65 items. The primary constructs of interest for the current study were student predisposition toward instructor feedback, perceptions of teaching presence in a current course, and motivation toward online courses. As described above, participants first reported on perceptions of teaching presence in the specific online course in which they received the online survey link. Participants then reported on general motivation toward online courses. Participants then reported on how they generally feel about receiving feedback from teachers. Finally, participants provided background information for use as covariates in the regression 
models, including age, sex, employment status, distance from campus, and reasons for taking online courses.

The online survey also included several items to better gain insight into the online students in the sample. The majority of participants had taken two or three online courses $(n=56)$, with 39 students reporting the current course as the first online course they had taken. The majority of participants were full-time students $(n=146)$. Roughly $80 \%$ of students in the sample reported working while in school, either part-time $(n=92)$ or full-time $(n=48)$. Participants also reported reasons for taking online courses. The two most popular reasons for taking an online course were the convenience $(n=58)$, and ability to fit work schedules $(n=54)$. Finally, participants were asked how far away (in miles) they lived from campus. Reported distance to campus ranged from zero miles to 188 miles $(M=24.84, M d n=15, S D=32.85)$. A total of 170 participants completed all of the necessary items to be included in the data for statistical analysis $(N=170)$.

Teaching presence. Teaching presence was measured using Shea et al.'s (2006) 17-item instructor teaching presence scale (TPS). The TPS was developed from Anderson et al.'s (2001) CoI framework, and measures two dimensions: instructional design/organization, and directed facilitation. In Shea et al.'s study, Cronbach's $\alpha$ reliability was reported as 0.97 for instructional design and organization, and 0.93 for directed facilitation. Participants ranked the teaching presence items on a Likert-type scale ( 1 = strongly disagree, 5 = strongly agree).

Motivation. Student motivation toward online courses was measured using Christophel's (1990) 12-item bi-polar Trait/State Motivation Scale (TSMS). The semantic differential type scale asked participants to select (on a scale of 1 to 7 ) the word that best described their feeling toward online courses (ex. Motivated-Unmotivated). For the three tests of the scale in Christophel's study, reliabilities for trait motivation ranged from 0.91 to 0.93 , and reliabilities for state motivation ranged from 0.95 to 0.96 . Since the focus in the current study was on student motivation toward online courses, the TSMS was used as a measure of student motivation toward online courses.

Instructor feedback. Student response to instructor feedback was measured using King et al.'s (2009) 27-item Instructional Feedback Orientation Scale (IFOS). The IFOS measures four dimensions of students' predisposition toward instructor feedback: retention, confidentiality, sensitivity, and utility. In King et al.'s validity study of the IFOS, $\alpha$ reliability was reported as 0.69 for retention, 0.74 for confidentiality, 0.86 for sensitivity, and 0.85 for utility. Continued support for the instrument in the FtF context appears in King's (2016) study on student perceptions of instructor feedback on student speeches.

\section{Preliminary Analysis}

For each of the scale variables, procedures related to examination of the factor structure of a scale were used to compare the expected correlation matrix, generated on the basis of the theoretical measurement model, to the observed matrix generated by the actual data (Nunnally \& Bernstein, 1994; Hunter, 1973; Hunter \& Cohen, 1969; Levine \& McCroskey, 1990).

A confirmatory factor analysis was calculated on the teaching presence items examining the two dimensions identified by Shea et al. (2006): instructional design/organization, and directed facilitation. In both cases, the fit statistics for the CFA suggested a weak model fit. Therefore, an exploratory factor analysis was calculated using Principal Axis Factoring (PAF) to provide insight into why the CFA models did not fit the data. The use of PAF suggested a clear one-factor solution for teaching presence that accounted for approximately $68 \%$ of the variance $(E V=11.56)$. The 
current data for the teaching presence construct indicates a best fit using a single factor model for the items, with a high reliability $(\alpha=.97, M=71.26, S D=13.86)$. Contrary to Shea et al.'s two factor representation of instructor teaching presence, the best representation in the current data involves the use of a single factor, or a unidimensional representation of the available data.

A confirmatory factor analysis was calculated on the motivation items. Despite expectations for a single factor solution, fit statistics for the CFA on the motivation items suggested a weak model fit. Again, an exploratory factor analysis was calculated using PAF to determine why the CFA models did not fit the data. The use of PAF suggested two potential factors, however one item cross-loaded weakly onto both factors (i.e., Unchallenged:Challenged). Examination of correlations between items suggested that the item could potentially be negatively impacting the scale, and removal of the item resulted in improved internal reliability $(\alpha=.93, M=36.01, S D=$ 13.24). Re-calculating the factor analysis, using PAF, resulted in a clear single factor that accounted for approximately $69 \%$ of the variance $(E V=6.50)$.

Finally, a series of confirmatory factor analyses were calculated on the instructor feedback items. Examination of fit statistics suggested that none of the four factors identified by King et al. (2009) (e.g., utility, sensitivity, confidentiality, retention) demonstrated acceptable fit. As with teaching presence and motivation, an exploratory factor analysis was then calculated, using PAF, to better understand why the CFA models did not adequately fit the data. Examination of the scree plot suggested a clear diminishing return after the third factor, however the items in the third factor were relatively weak and/or cross-loaded onto the second factor. With weakly loaded items removed, the PAF on the instructor feedback items found two subscales; one concerned with feedback valence (the degree of positive and negative focus of the feedback, $\alpha=.96, M=35.85$, $S D=6.04$ ) and one concerned with emotionality (the impact of the message on student feelings, $\alpha$ $=.93, M=31.74, S D=7.71$ ). Therefore, contrary to previous research utilizing four dimensions, the current data utilizes a two factor representation of student predisposition to instructor feedback.

\section{Statistical Analysis}

Correlations were calculated for continuous variables, and appear in Table 1. A hierarchical multiple regression was calculated using the enter method to test the study hypotheses (Table 2). To better isolate the impact of the variables of interest, three models, consisting of two blocks of covariates and a third block of the variables of interest, were calculated. Student demographic covariates (age, sex) were entered in the first block. A second block included covariates relating to students' college careers; specifically, potential antecedents for enrolling in online courses, and previous experience with online courses. Finally, the third block of the hierarchical multiple regression included the constructs of interest: teaching presence, and the two instructor feedback variables (valence and emotionality). Given the number of predictors in the hierarchical multiple regression models, the sample provided appropriate power to identify medium to large effect sizes at $\alpha=.01$ (Cohen, 1992). 


\begin{tabular}{llllllll}
\hline Variables & 1 & 2 & 3 & 4 & 5 & 6 & 7 \\
\hline 1. Age & & & & & & & \\
2. College Year & .05 & & & & & & \\
3. Distance & $.30^{* *}$ & -.00 & & & & & \\
4. Online Courses & $.34^{* *}$ & $.40^{* *}$ & $.21^{*}$ & & & & \\
5. Presence & .06 & $-.19^{*}$ & .00 & -.01 & & & \\
6. Motivation & $-.28^{* *}$ & .07 & -.15 & -.15 & $-.33^{* *}$ & & .13 \\
7. Feedback Valence & .06 & -.02 & .05 & .05 & $.29^{* *}$ & -.13 & \\
8. Feedback Emotion & $.15^{*}$ & .05 & .00 & .09 & .13 & $-.29^{* *}$ & $.28^{* *}$ \\
\hline
\end{tabular}

Table 1. Correlation Matrix

Notes: $* p<.05 . * * p<.01$.

\begin{tabular}{|c|c|c|c|c|c|c|c|c|c|}
\hline \multirow[b]{2}{*}{ Variable } & \multicolumn{3}{|c|}{ Model 1} & \multicolumn{3}{|c|}{ Model 2} & \multicolumn{3}{|c|}{ Model 3} \\
\hline & $B$ & $S E B$ & $\beta$ & $B$ & $S E B$ & $\beta$ & $B$ & $S E B$ & $\beta$ \\
\hline Sex & -0.04 & 0.18 & -.02 & 0.01 & 0.18 & 0.01 & 0.04 & 0.16 & 0.02 \\
\hline Age & -0.42 & 0.13 & $-.29 * *$ & -0.24 & 0.16 & -0.17 & -0.21 & 0.14 & -0.15 \\
\hline Employment & & & & -0.06 & 0.14 & -0.04 & -0.12 & 0.12 & -0.08 \\
\hline Student Status & & & & 0.37 & 0.26 & 0.15 & 0.10 & 0.23 & 0.04 \\
\hline College Year & & & & 0.16 & 0.10 & 0.16 & 0.11 & 0.09 & 0.11 \\
\hline Distance & & & & 0.00 & 0.00 & -0.02 & -0.00 & 0.00 & -0.06 \\
\hline Online Courses & & & & -0.14 & 0.09 & -0.15 & -0.10 & 0.08 & -0.11 \\
\hline Presence & & & & & & & -0.36 & 0.08 & $-0.38 * *$ \\
\hline Feedback V & & & & & & & 0.02 & 0.08 & 0.02 \\
\hline Feedback E & & & & & & & -0.25 & 0.08 & $-0.26 * *$ \\
\hline$\Delta R^{2}$ & & 0.06 & & & 0.09 & & & 0.2 & \\
\hline $\begin{array}{l}F \text { for change in } \\
R^{2}\end{array}$ & & $5.16^{* *}$ & & & 1.43 & & & 11.5 & \\
\hline
\end{tabular}

Table 2. Hierarchical Regression Analysis Predicting Student Motivation toward Online Courses

$(\mathrm{N}=170)$

Notes: Employment $=$ employment status. Student status $=$ part-time or full-time student. Distance $=$ distance from campus

(in miles). Online courses $=$ number of online courses taken. Presence $=Z$-standardized teaching presence variable. Feedback V

$=$ Z-standardized feedback valence variable. Feedback E $=$ Z-standardized feedback emotionality variable. $* p<.05 . * * p<.01$. 


\section{Results}

Both study hypotheses were tested through calculating a hierarchical multiple regression consisting of three blocks (Table 2). Controlling for the influence of the covariates in the first two blocks, the hierarchical multiple regression produced a significant model including the feedback variables and teaching presence, $F(10,105)=5.74, p<.001, R^{2}=.29$. VIF statistics for the model were all within acceptable ranges, indicating no significant issues with multicollinearity. Hierarchical multiple regression results provided mixed support for the study hypotheses.

First, $\mathrm{Hl}$ predicted that higher levels of teaching presence in current online courses would predict higher student motivation toward online courses more generally. A relationship between perceptions of teaching presence in current courses and motivation toward online courses was identified in the current data. However, contrary to expectations, teaching presence significantly, negatively predicted student motivation toward online courses $(\beta=-.38, t(105)=-4.63, p<.01$, $95 \% \mathrm{CI}[-.52,-.21])$. The current data therefore suggests that higher levels of perceived teaching presence in a current online course significantly, negatively predict student motivation toward online courses. Though a significant relationship between teaching presence and student motivation in online courses was identified, the predictive influence did not occur in the hypothesized direction. Therefore, the observation that teaching presence negatively predicted student motivation fails to support $H 1$.

Second, $H 2$ predicted that negative student predispositions to instructor feedback would decrease student motivation toward online courses. Results from the hierarchical multiple regression identified feedback emotionality $(\beta=-.26, t(105)=-3.13, p<.01,95 \%$ CI $[-.41,-.09])$ as a negative predictor of student motivation toward online courses. Therefore, the greater degree to which students react negatively emotionally to instructor feedback, the less motivated they appear toward online courses. As negative emotional student predisposition to instructor feedback predicted lower motivation toward online courses, $H 2$ was supported.

\section{Discussion}

The current data suggest that perception of teaching presence and negative student emotional predisposition toward instructor feedback significantly, negatively predicts student motivation toward online courses. Though these findings are described below, it is again worth noting that the primary measures used on the constructs of interest (e.g., teaching presence, motivation, and predisposition to instructor feedback) did not fit neatly into pre-existing conceptualizations of these constructs noted in previous research. Teaching presence (Shea et al., 2006) loaded onto a single factor, rather than two. Motivation (Christophel, 1990) did not load cleanly onto a single factor until an item relating to "challenge" was removed. A number of items on the predisposition to instructor feedback measure did not load, or weakly cross-loaded on multiple factors, causing two factors to neatly emerge rather than the four identified by King et al. (2009). Despite these initial measurement issues, statistical analysis on the current data suggest that student predisposition to receiving instructor feedback and student perceptions of teaching presence provide strong prediction of student motivation toward online courses.

The significant, negative relationship between teaching presence and motivation directly contradicted $H 1$. However, understanding of this finding may be found in the different perspectives that students and instructors may bring to online courses (Otter et al., 2013). Given the multitude of challenges involved with online teaching and learning (Bolliger \& Wasilik, 2009; Sherblom, 2010), many instructors teaching online may strive to replicate what they do in traditional FtF 
course settings as closely as possible in their online courses. Attempting to replicate the FtF classroom in the online learning environment thus likely involves using a variety of different communication channels (e.g., audio, video) in hopes to increase the "richness" of the communication experience in the course. According to Media Richness Theory (MRT; Daft \& Lengel, 1986; Daft, Lengel, \& Trevino, 1987), messages containing complex information are best suited to "rich" mediums, where verbal and nonverbal messages are simultaneously exchanged by communicators, as found FtF. Such an approach toward designing and facilitating an online course likely intuitively makes sense to instructors, as the course material would seem to reflect MRT's notion of complex information that would warrant a rich medium in order to be effectively sent and received. However, some previous research (Allen et al., 2004) suggests that using as many channels as possible, in attempt to re-create the traditional FtF classroom as closely as possible online, might not increase student satisfaction with the modality. As Feaster (2010) suggests, having multiple channels available can potentially influence an interaction, but ultimately, individuals' preferences, and actual use of the channels, may determine the result. Rather than focusing on the number of channels used, or the perceived richness of the channels used, in an online course, perhaps the focus should shift toward whether students are satisfied with the communication they receive from the instructor, regardless of the channel(s) used. Given the results of the current study, it is possible that many students taking online courses may not desire an online course structure that attempts to replicate the FtF class experience. These students might, therefore, not actually desire more "richness," and may be perfectly satisfied with less rich communication between students and instructors.

A desire to "opt out" of the traditional FtF class experience, for any number of personal reasons, could form the basis for why some students enroll in an online course in the first place. For these students, any attempts to replicate the $\mathrm{FtF}$ class environment could potentially serve to decrease motivation. Relatedly, perceptions of teaching presence may actually be counterproductive to student motivation for students who may not conceptualize the student-instructor relationship the same online as FtF, nor wish a similar student-instructor interpersonal relationship (Frymier \& Houser, 2000). In light of previous research on student-instructor power relationships online (Cole et al., 2015) aspects of teaching presence that reflect instructor control over the course may especially decrease student motivation. Therefore, instructor communication behaviors focused on direction and clarity (Poulos \& Mahony, 2008; Sheridan \& Kelly, 2010), no matter how well intentioned, may ultimately serve to decrease student motivation toward online courses. Students may begin an online course believing that the online course format allows them the autonomy and ability to explore concepts on their own, without the constraints of a FtF class experience (Otter et al., 2013). For these students, online course design structures and communication behaviors put into place by a well-meaning instructor to increase teaching presence could actually result in decreased motivation toward online courses more generally. The persistence of external constraints on their learning online may make them feel less independent and autonomous in online courses than they had hoped. Highly structured online course design and direct, clear online instructor communication may reinforce student perceptions of instructor control, as well as contradict a priori expectations of student autonomy online with new perceptions of dependency on the instructor to pass the course. If some students "opt in" to online courses because they actually prefer less "richness," and perhaps a less distinct student-instructor relationship, it might no longer be particularly surprising that the current results did not suggest a significant difference between the instructor as course designer and the instructor as a guide to discussion on the course content. Likewise, it may no longer be surprising that these students 
would feel less motivated toward online courses more generally, if their perceptions of what an online course should be are not met in a current online course.

Issues relating to perceptions of student autonomy may be reflected in the student predisposition to instructor feedback results as well. As hypothesized, student predisposition toward instructor feedback significantly, negatively predicted student motivation toward online courses in the current study. As instructor feedback can potentially be face-threatening and demotivating FtF (Kerssen-Griep \& Witt, 2012; Malachowski et al., 2013; Trees et al., 2009), replicating such findings in the less nonverbally rich online course context (Pratt et al., 1999; Sherblom, 2010) should be expected. Again, a specific focus on clarity in communication in the online course context (Poulos \& Mahony, 2008; Sheridan \& Kelly, 2010), and the likely asynchronous delivery/receipt of online feedback, reduces opportunity for instructors to skillfully manage face-threats (Kerssen-Griep \& Witt, 2012; Trees et al., 2009) while delivering online feedback to students. Such findings, though not necessarily surprising, are especially noteworthy given increasing student-instructor communication (including grades and feedback) taking place online through technology like a CMS, even in FtF courses (i.e., "tech enhanced" courses).

Finally, contrary to previous research using King et al.'s (2009) Instructional Feedback Orientation Scale (IFOS), factor analysis of the scale items in the current data identified two distinct subscales with high reliability; the degree of positive and negative focus of the feedback (i.e., valence) and student feelings following the feedback (i.e., emotionality). Only how students generally feel emotionally about instructor feedback significantly predicted motivation toward online courses. However, the significant correlation observed between feedback valence and emotionality warrants further consideration. Feedback emotionality may result as an outcome of feedback valence. Therefore, feedback valence may not directly influence student motivation toward online courses since the emotional state resultant from student appraisals of instructor feedback offers a more direct, predictive influence on a student affect variable like motivation.

\section{Limitations \& Future Directions}

Results of the current study offer several avenues for future research. However, the current study has several limitations as well. Previous research suggests that increasing student motivation improves educational outcomes related to cognitive learning (Allen et al., 2006). One limitation of the current study involves the lack direct measures involving issues relating to cognitive learning outcomes. Subsequent research should aim to include measures of cognitive learning, as well as direct measures on student performance outcomes such as grades and retention. Though not necessarily a separate outcome, better understanding student motivation online may become an important issue related to both student competence and student retention, both central concerns of educational institutions.

A further limitation of the current study concerns how long-term implications of the teaching presence construct on student motivation toward online courses long-term is inferred rather than examined directly. Measurement across the lifespan of a degree, with multiple instructors and many different courses, implies the influence of programmatic attempts to increase and maintain levels of motivation. Longitudinal research, examining the influence of the predictive variables identified in the current study across all courses, as well as courses in the degree program, could assess the prediction about whether or not perceptions of teaching presence (as well as the quality of student-instructor communication) contributes to degree completion. 
Relatedly, as participants self-reported on the class from which they received the study survey for the teaching presence items, the content and course design of the online courses in this study where not held constant. Therefore, there was no variable that could capture the extent to which different types of media (e.g., instructor videos; interactive slides etc.) were utilized in the referenced online course. Future research may wish to attempt a controlled experimental design where the course material and course design is manipulated, in attempt to better capture any potential influences on a construct like teaching presence.

A final, related, limitation of the current study concerns the sample characteristics. The majority of participants represented traditional college ages. However, despite the large number of traditionally aged students, student age significantly predicted motivation toward online courses in the first hierarchical regression model. Perhaps, had nontraditionally aged students been more represented, student age would have maintained its predictive influence on motivation toward online. Future research could benefit from testing prediction on student motivation toward online courses focusing on specific populations of interest to online education, such as new traditionally aged college students (approximately 18-22 years old), new returning students older than 22 years old, and/or students enrolled in their first online courses at any level of their college careers. Examining these specific populations could provide more insight into population specific predictors, which could further inform potential online course, and program, attrition interventions.

\section{Conclusion}

The problematic issue identified in the current study, through issues of measurement and hypothesis testing, perhaps lies in the idea that online teaching and learning simply takes what is done in the traditional $\mathrm{FtF}$ classroom and translates it to the online learning environment. As student motivation appears linked to student performance (Bolkan et al., 2016) and the number of college students taking at least one online course continues to increase (Allen \& Seaman, 2015), the need to better understand how to assist in motivating students in online courses continues to represent a major challenge worthy of continued research. Though many issues existing in $\mathrm{FtF}$ courses find a similar underlying set of considerations and applications in online courses, the online learning environment offers its own set of challenges, as well as opportunities. As metaanalyses comparing online and $\mathrm{FtF}$ learning established similar levels of cognitive learning and student satisfaction (Allen et al., 2002, Allen et al., 2004), the challenge for online instructors becomes how to best facilitate positive student outcomes. This research furthers that understanding by (1) supporting previous research in FIT (Kluger \& DeNisi, 1996) by identifying negative emotional predisposition to instructor feedback as a significant negative predictor of student motivation toward online courses, and; (2) indicating that recognizing high levels of teaching presence in a current online course does not guarantee high student motivation toward online courses more generally. 


\section{References}

Allen, I. E., \& Seaman, J. (2015, February). Grade level: Tracking online education in the United States. Retrieved from http://onlinelearningconsortium.org/read/survey-reports2014/

Allen, M., Bourhis, J., Burrell, N., \& Mabry, E. (2002). Comparing student satisfaction with distance education to traditional classrooms in higher education: A meta-analysis. The American Journal of Distance Education, 16, 83-97. doi: 10.1207/S15389286AJDE1602_3

Allen, M., Mabry, E., Mattrey, M., Bourhis, J., Titsworth, S., \& Burrell, N. (2004). Evaluating the effectiveness of distance learning: A comparison using meta-analysis. Journal of Communication, 54, 402-420. doi: 10.1111/j.1460-2466.2004.tb02636.x

Allen, M., Witt, P. L., \& Wheeless, L. R. (2006). The role of teacher immediacy as a motivational factor in student learning: Using meta-analysis to test a causal model. Communication Education, 55, 21-31. doi: 10.1080/03634520500343368

Anderson, T., Rourke, L., Garrison, D. R., \& Archer, W. (2001). Assessing teaching presence in a computer conferencing context. Journal of Asynchronous Learning Networks, 5(2), 117.

Bolkan, S., Goodboy, A. K., \& Kelsey, D. M. (2016). Instructor clarity and student motivation: Academic performance as a product of students' ability and motivation to process instructional material. Communication Education, 65, 129-148. doi: 10.1080/03634523.2015.1079329

Bolliger, D. U., \& Wasilik, O. (2009). Factors influencing faculty satisfaction with online teaching and learning in higher education. Distance Education, 30, 103-116. doi: $10.1080 / 01587910902845949$

Brophy, J. (1983). Conceptualizing student motivation. Educational Psychologist, 18, 200-215. doi: 10.1080/00461528309529274

Christophel, D. M. (1990). The relationships among teacher immediacy behaviors, student motivation, and learning. Communication Education, 39, 323-340. doi: $10.1080 / 03634529009378813$

Christophel, D. M., \& Gorham, J. (1995). A test-retest analysis of student motivation, teacher immediacy, and perceived sources of motivation and demotivation in college classes. Communication Education, 44, 292-306. doi: 10.1080/03634529509379020

Cohen, J. (1992). A power primer. Psychological Bulletin, 112, 155-159. doi: 10.1037/00332909.112.1.155

Cole, A. W. (2016). Testing the impact of student preference for face-to-face communication on online course satisfaction. Western Journal of Communication, 80, 619-637. doi:10.1080/10570314.2016.1186824

Cole, A. W., Kim, S. -Y., \& Priddis, D. (2015). Examining the relationship between students' perceptions of instructor communication of power online and student online course endorsement. Pennsylvania Communication Annual, 71, 11-36. 
Cole, A. W., \& Timmerman, C. E. (2015). What do current college students think about MOOCs? MERLOT Journal of Online Learning and Teaching, 11, 188-201.

Daft, R. L., \& Lengel, R. H. (1986). Organizational information requirements: Media richness and structural design. Management Science, 32, 554-571. doi:10.1287/mnsc.32.5.554

Daft, R. L., Lengel, R. H., \& Trevino, L. K. (1987). Message equivocality, media selection, and manager performance: Implications for information systems. MIS Quarterly, 11, 355366. doi: $10.2307 / 248682$

Dennen, V. P. (2005). From message posting to learning dialogues: Factors affecting learner participation in asynchronous discussion. Distance Education, 26, 127-148. doi: $10.1080 / 01587910500081376$

Easton, S. S. (2003). Clarifying the instructor's role in online distance learning. Communication Education, 52, 87-105. doi: 10.1080/03634520302470

Feaster, J. (2010). Expanding the impression management model of communication channels: An information control scale. Journal of Computer-Mediated Communication, 16, 115138. doi: 10.1111/j.1083-6101.2010.01535.X

Frisby, B., N., Limperos, A. M., Record, R. A., Downs, E., \& Kerscmar, S. E. (2013). Students' perceptions of social presence: Rhetorical and relational goals across three mediated instructional designs. MERLOT Journal of Online Learning and Teaching, 9, 468-480.

Frymier, A. B., \& Houser, M. L. (2000). The teacher-student relationship as an interpersonal relationship. Communication Education, 49, 207-219. doi: 10.1080/03634520009379209

Garrison, D. R., Anderson, T., \& Archer, W. (1999). Critical inquiry in a text-based environment: Computer conferencing in higher education. The Internet and Higher Education, 2, 87-105. doi: 10.1016/s1096-7516(00)00016-6

Garrison, D. R., Cleveland-Innes, M., \& Fung, T. S. (2010). Exploring causal relationships among teaching, cognitive and social presence: Student perceptions of the community of inquiry framework. Internet and Higher Education, 13, 31-36. doi: 10.1016/j.iheduc.2009.10.002

Haleta, L. L. (1996). Student perceptions of teachers' use of language: The effects of powerful and powerless language on impression formation and uncertainty. Communication Education, 45, 16-28. doi: 10.1080/03634529609379029

Hazel, M., Crandall, H. M., \& Caputo, J. S. (2014). The influence of instructor social presence and student academic entitlement on teacher misbehaviors in online courses. Southern Communication Journal, 79, 311-326. doi: 10.1080/1041794X.2014.914563

Hosler, K. A., \& Arend, B. D. (2012). The importance of course design, feedback, and facilitation: Student perceptions of the relationship between teaching presence and cognitive presence. Educational Media International, 49, 217-229. doi: 10.1080/09523987.2012.738014

Hunter, J. E. (1973). Methods of reordering the correlation matrix to facilitate visual inspection and preliminary cluster analysis. Journal of Educational Measurement, 10, 51-61. doi: 10.1111/j.1745-3984.1973.tb00782.x 
Hunter, J. E., \& Cohen, S. H. (1969). PACKAGE: A system of computer routines for the analysis of correlational data. Educational and Psychological Measurement, 29, 697-700. doi: $10.1177 / 001316446902900315$

Kerssen-Griep, J., \& Witt, P. L. (2012). Instructional feedback II: How do instructor immediacy cues and facework tactics interact to predict student motivation and fairness perceptions? Communication Studies, 63, 498-517. doi: 10.1080/10510974.2011.632660

King, P. E. (2016). When do students benefit from performance feedback? A test of feedback intervention theory in speaking improvement. Communication Quarterly, 64, 1-15. doi: $10.1080 / 01463373.2015 .1078827$

King, P. E., Schrodt, P., \& Weisel, J. J. (2009). The instructional feedback orientation scale: Conceptualizing and validating a new measure for assessing perceptions of instructional feedback. Communication Education, 58, 235-261. doi: 10.1080/03634520802515705

Kluger, A. N., \& DeNisi, A. (1996). The effects of feedback interventions on performance: A historical review, a meta-analysis, and a preliminary feedback intervention theory. Psychological Bulletin, 119, 254-284. doi: 10.1037/0033-2909.119.2.254

Levine, T. R., \& McCroskey, J. C. (1990). Measuring trait communication apprehension: A test of rival measurement models of the PRCA-24. Communication Monographs, 57, 62-72. doi: 10.1080/03637759009376185

Malachowski, C. C., Martin, M. M., \& Vallade, J. I. (2013). An examination of students' adaptation, aggression, and apprehension traits with their instructional feedback orientations. Communication Education, 62, 127-147. doi:

10.1080/03634523.2012.748208

Mandernach, B. J., Gonzales, R. M., \& Garrett, A. L. (2006). An examination of online instructor presence via threaded discussion participation. MERLOT Journal of Online Learning and Teaching, 4, 248-260.

Martin, M. M., Chesebro, J. L., \& Mottet, T. P. (1997). Students' perceptions of instructors' socio-communicative style and the influence on instructor credibility and situational motivation. Communication Research Reports, 14, 431-440. doi: 10.1080/08824099709388686

Morreale, S., Staley, C., Stavrositu, C., \& Krakowiak, M. (2015). First-year college students' attitudes toward communication technologies and their perceptions of communication competence in the $21^{\text {st }}$ century. Communication Education, 64, 107-131. doi: $10.1080 / 03634523.2014 .978799$

Nunnally, J.C., \& Bernstein, I. H. (1994). Psychometric theory ( $3^{\text {rd }}$ ed.). New York: McGrawHill.

Otter, R. R., Seipel, S. Graeff, T., Alexander, B., Boraiko, C., Gray, J., Petersen, \& Sadler, K. (2013). Comparing student and faculty perceptions of online and traditional courses. Internet and Higher Education, 19, 27-35. doi: 10.1016/j.iheduc.2013.08.001

Plax, T. G., Kearney, P., McCroskey, J. C., \& Richmond, V. P. (1986). Power in the classroom VI: Verbal control strategies, nonverbal immediacy and affective learning. Communication Education, 35, 43-55. doi: 10.1080/03634528609388318 
Poulos, A., \& Mahony, M. J. (2008). Effectiveness of feedback: The students' perspective. Assessment \& Evaluation in Higher Education, 33, 143-154. doi: $10.1080 / 02602930601127869$

Pratt, L., Wiseman, R. L., Cody, M. J., \& Wendt, P. F. (1999). Interrogative strategies and information exchange in computer-mediated communication. Communication Quarterly, 47, 46-66. doi: /10.1080/01463379909370123

Reddy, D. M., Pfeiffer, H. M., Fleming, R., Ports, K. A., Pedrick, L. E., Barnack-Tavlaris, J. L., Jirovec, D. L., Helion, A. M., \& Swain, R. A. (2013). "U-Pace” instruction: Improving student success by integrating content mastery and amplified assistance. Journal of Asynchronous Learning Networks, 17, 147-154.

Robinson, S., Pope, D., \& Holyoak, L. (2013). Can we meet their expectations? Experiences and perceptions of feedback in first year undergraduate students. Assessment \& Evaluation in Higher Education, 38, 260-272. doi: 10.1080/02602938.2011.629291

Shea, P., Li, C. S., \& Pickett, A. (2006). A study of teaching presence and student sense of learning community in fully online and web-enhanced college courses. Internet and Higher Education, 9, 175-190. doi: 10.1016/j.iheduc.2006.06.005

Sherblom, J. C. (2010). The computer-mediated communication (CMC) classroom: A challenge of medium, presence, interaction, identity, and relationship. Communication Education, 59, 497-523. doi: 10.1080/03634523.2010.486440

Sheridan, K., \& Kelly, M. A. (2010). The indicators of instructor presence that are important to students in online courses. MERLOT Journal of Online Learning and Teaching, 6, 767779 .

Smith, C. D., \& King, P. E. (2004). Student feedback sensitivity and the efficacy of feedback interventions in public speaking performance improvement. Communication Education, 53, 203-216. doi: 10.1080/0363452042000265152

Thompson, P. (2013). The digital natives as learners: Technology use patterns and approaches to learning. Computers \& Education, 65, 12-33. doi: 10.1016/j.compedu.2012.12.022

Trees, A. R., Kerssen-Griep, J., \& Hess, J. (2009). Earning influence by communicating respect: Facework's contributions to effective instructional feedback. Communication Education, 58, 397-416. doi: 10.1080/03634520802613419

U.S. Department of Education. (2014). Enrollment in distance education courses, by state: Fall 2012 (NCES 2014-023). National Center for Education Statistics. Retrieved from http://nces.ed.gov/pubs2014/2014023.pdf

Vaughan, N. D., Cleveland-Innes, M., \& Garrison, D. R. (2013). Teaching in blended learning environments: Creating and sustaining communities of inquiry. Edmonton, AB: AU Press, Athabasca University. 